\title{
Graduate programs in biophotonics: unique transdisciplinary training in applied photonics for the life sciences
}

\section{Andréanne Deschênes, Flavie Lavoie-Cardinal, Mario Méthot, Paul De Koninck}

Andréanne Deschênes, Flavie Lavoie-Cardinal, Mario Méthot, Paul De Koninck, "Graduate programs in biophotonics: unique transdisciplinary training in applied photonics for the life sciences," Proc. SPIE 11143, Fifteenth Conference on Education and Training in Optics and Photonics: ETOP 2019, 1114327 (2 July 2019); doi: 10.1117/12.2523459 


\title{
Graduate programs in biophotonics : unique transdisciplinary training in applied photonics for the life sciences
}

\author{
Andréanne Deschênes ${ }^{\mathrm{a}}$, Flavie Lavoie-Cardinal ${ }^{\mathrm{a}}$, Mario Méthot ${ }^{\mathrm{a}}$, and Paul De Koninck ${ }^{\mathrm{a}, \mathrm{b}}$ \\ ${ }^{a}$ CERVO Brain Research Centre,Québec (Qc),Canada

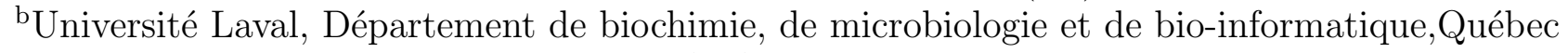 \\ (Qc), Canada
}

\begin{abstract}
In 2008, Université Laval launched the first and only graduate programs in biophotonics in Canada. This initiative is dedicated to the training of a new generation of highly qualified researchers at the interface of life sciences and optics. It also stemmed from the strong expertise of the University in optics/photonics, its major investments in state-of-the art biophotonics infrastructure and technologies, and its desire to promote multidisciplinary training of graduate students. The programs are hosted by the Faculty of Science and Engineering in collaboration with the Faculty of Medicine, regrouping professors from 3 Faculties and 10 departments at Université Laval. The biophotonics graduate programs offer students from a wide variety of scientific backgrounds the opportunity to train in highly skilled research teams on projects that bridge the gap between traditional research fields. They benefit from transdisciplinary training opportunities in the fields of physics, chemistry, biology, biochemistry, neurosciences, medicine, engineering and ethics.
\end{abstract}

Keywords: Biophotonics, Graduate training programs, multidisciplinary training

\section{INTRODUCTION}

Biophotonics is the application of optics and photonics to life sciences for basic research, biomedical diagnosis and intervention, and agro-industrial applications. This transdisciplinary research field resides at the interface of physics, biology, chemistry, and engineering, having impacts in diverse domains such as ecology, environment, food industry and medicine. To respond to the urgent need for specialized expertise in biophotonics, Université Laval created in 2008, two graduate programs (MSc and PhD) in biophotonics. These programs, led by the Faculty of Science and Engineering in collaboration with the Faculty of Medicine, offer personalized training in optics/photonics and life sciences to students from many disciplines such as physics, biochemistry, biomedical sciences, and engineering. Trainees with a life science background develop an understanding of the optical tools they can use to study biological problems, while trainees with a physical science or engineering background gain an understanding in the biological problems that can be studied and solved with optical tools and the associated challenges. Trainees enrolled in the biophotonics graduate programs are involved in transdisciplinary research projects. Supervision of the research projects is achieved through mandatory co-mentorship from two principal investigators having complementary expertise, one in life sciences and the other in physical sciences or engineering. Students also have the opportunity to participate in an advanced, biophotonics summer school at the Neurophotonics Centre in Quebec City to acquire hands-on multidisciplinary experience with various methods in the field. The biophotonics initiative at Université Laval was precursor to the Sentinel North transdisciplinary strategy (funded by the Canadian First Excellence Research Fund - CFERF).

The opportunities for innovation in biophotonics are substantial, prompting many companies to invest in the development of tools or processes exploiting light to enable measurements and manipulation of animal behavior, cellular and molecular processes that were previously impossible with other approaches. The biophotonics programs are exploiting these developments to train a new generation of researchers to meet the transdisciplinary needs of the society and industry.

Further author information: (Send correspondence to P.D.K.)

P.D.K.: E-mail: Paul.DeKoninck@neuro.ulaval.ca

Fifteenth Conference on Education and Training in Optics and Photonics: ETOP 2019, edited by

Anne-Sophie Poulin-Girard, Joseph A. Shaw, Proc. of SPIE Vol. 11143, 1114327 - (c) 2019

SPIE, ICO, IEEE, OSA · CCC code: 0277-786X/19/\$18 · doi: 10.1117/12.2523459

Proc. of SPIE Vol. $111431114327-1$

Downloaded From: https://www.spiedigitallibrary.org/conference-proceedings-of-spie on 26 Apr 2023 


\section{PROGRAM STRUCTURE}

The biophotonics graduate programs comprise 45 credits for the MSc and 90 credits for PhD degree. At the MSc level, 12 credits are assigned for courses, seminars and exams, while 33 are dedicated to their research activities. At the $\mathrm{PhD}$ level, 6 credits are assigned for courses, while 84 are for research activities. The programs have trained thus far $29 \mathrm{MSc}$ and $13 \mathrm{PhD}$ students. As shown in Figure 1, graduate students in the biophotonics programs have undergraduate degrees in various fields of science and engineering (eg. biology, biochemistry, microbiology, biomedical sciences, chemistry, physics, engineering).

One of the goals of the programs is to break the barriers of language between these disciplines and to give the trainees the opportunity to gain transdisciplinary knowledge. Their course curriculum is designed to provide them with complementary training according to their undergraduate degrees (Fig. 2). To ensure the largest flexibility, a customized series of short courses (1 credit each) is offered to the trainees, according to their needs. These modules are designed to provide the students with expertise in complementary disciplines, either from life sciences, physical sciences or engineering.

For example, courses in physical sciences such as Classical optics, Lasers, Guided optics, are offered to students with a life science background, while courses, such as Cell biology, Microbiology, Immunology and virology, or Biochemistry are offered to students with physics and engineering backgrounds.

Two online courses were also conceived for the biophotonics programs. The first one, Introduction to biophotonics, offers 13 problem-oriented modules covering issues or challenges in the life sciences or medicine that can be addressed using tools in optics and photonics for research, diagnosis, or treatment. The proposed solutions and techniques are presented and developed using scientific results and methodology. This transdisciplinary course is also offered to all undergraduate programs in Science and Engineering or Medicine. A second online course, Cell Biology, was conceived to provide basic knowledge in cellular and molecular biology, genetics, biochemistry and metabolisms to students with a physics or engineering background. Additionally, students have the option to choose special topics in biophotonics or out-of-program courses, such as summer/winter schools to further enrich their training (Fig.2).

A Undergraduate degreees

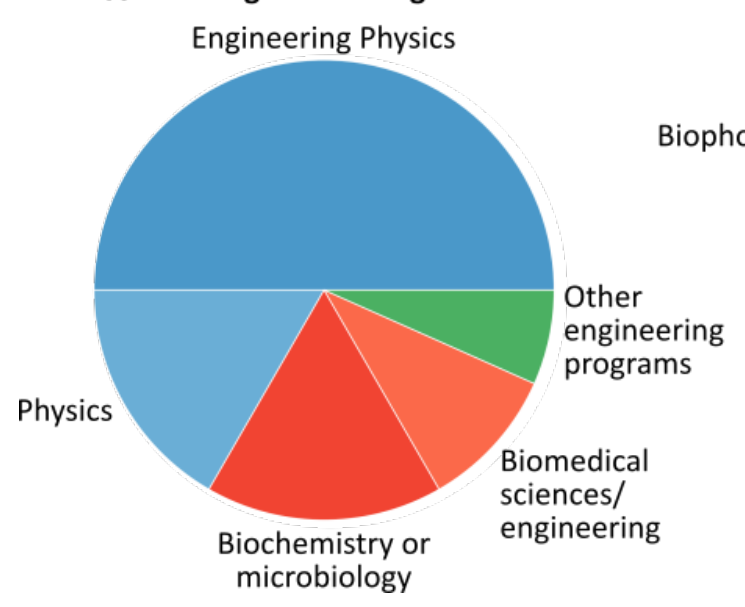

B Master's degreees

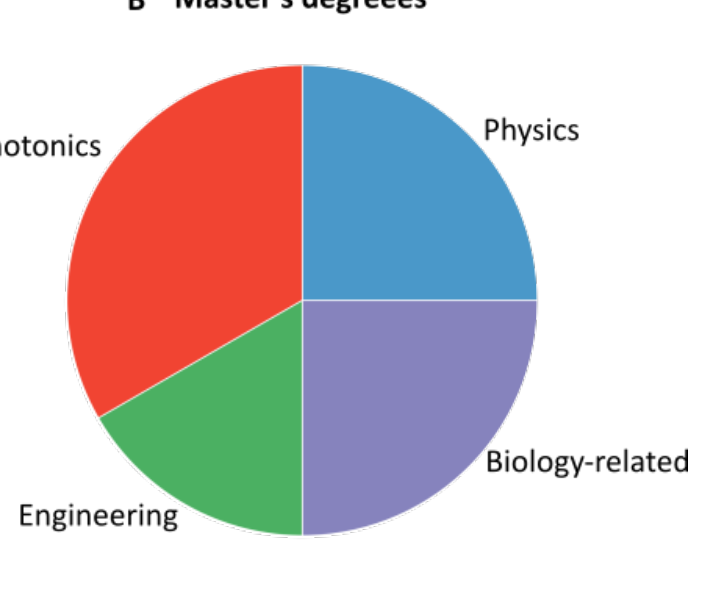

Figure 1. Prior diplomas of students before their enrolment in the A) MSc, and B) PhD in biophotonics

\section{TRANSDISCIPLINARY RESEARCH}

A strong component of the training experience for the students in biophotonics is the research environment, which is highly multidisciplinary. Professors from three different faculties (Science and Engineering, Medicine and Pharmacy) and 10 departments have supervised trainees of the biophotonics programs (Fig. 3). In addition to the Université Laval main campus, principal investigators also have laboratories in four affiliated research centres, the CERVO Brain research centre, the centre for optics, photonics and lasers (COPL), INO and Centre 
A

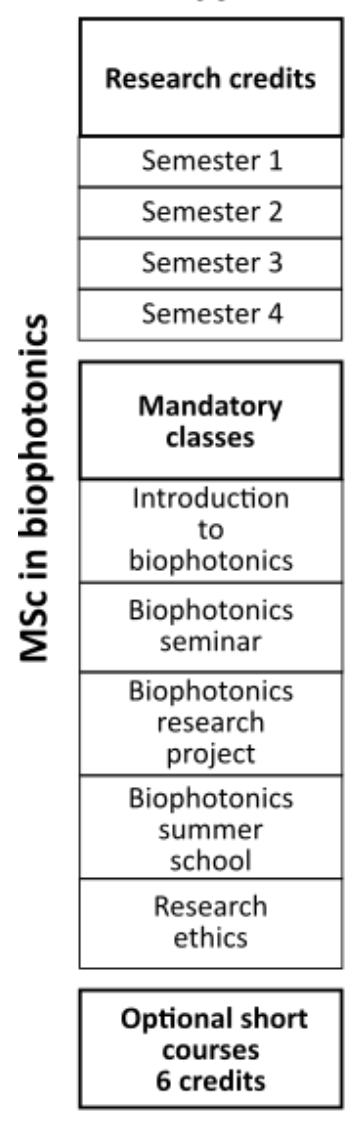

B

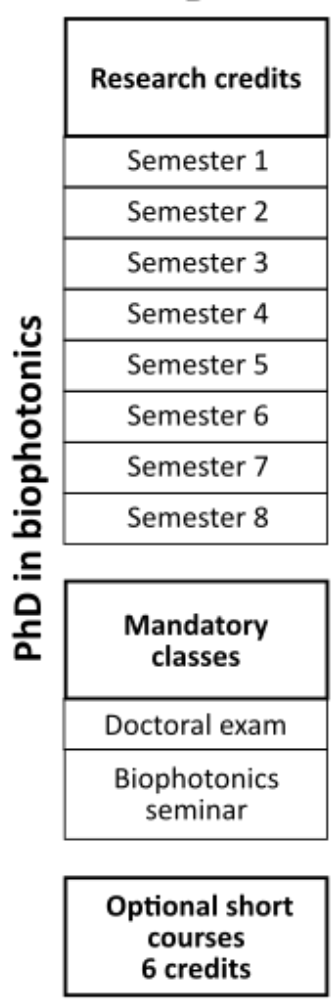

C

\begin{tabular}{|c|}
\hline $\begin{array}{l}\text { Option classes } \\
6 \text { choices from: }\end{array}$ \\
\hline Classical optics \\
\hline Guided optics \\
\hline Laser \\
\hline $\begin{array}{l}\text { Linear and } \\
\text { non-linear } \\
\text { tissue optics }\end{array}$ \\
\hline $\begin{array}{l}\text { Biomedical } \\
\text { imaging }\end{array}$ \\
\hline $\begin{array}{c}\text { Optical } \\
\text { spectroscopy }\end{array}$ \\
\hline Signal analysis \\
\hline Cell biology \\
\hline $\begin{array}{c}\text { Genetics, } \\
\text { genomics and } \\
\text { molecular biology }\end{array}$ \\
\hline $\begin{array}{l}\text { Microbiology, } \\
\text { immunology } \\
\text { and virology }\end{array}$ \\
\hline Biochemistry \\
\hline $\begin{array}{l}\text { Light and } \\
\text { environment }\end{array}$ \\
\hline $\begin{array}{l}\text { Special topics } \\
\text { in biophotonics } \\
\text { and out-of- } \\
\text { program classes }\end{array}$ \\
\hline
\end{tabular}

Figure 2. Curriculum of the biophotonics programs. Adapted from Ref. 1 and Ref. 2

Hospitalier Universitaire de Québec. Co-mentorship is mandatory for every student of the programs, such that one mentor is from the life science sector and the other is from the physical science or engineering sector. The students are also accompanied by a thesis committee composed of 4 professors, 2 being the co-supervisors; the other 2 members of the committee have complementary expertise to ensure a true transdisciplinary training for the students.

The research conducted by the students in biophotonics has lead to multiple transdisciplinary projects. These research projects have resulted in several publications in multidisciplinary research journals such as Nature Communications, Neurophotonics, Journal of Biomedical Optics, PLoS One and Journal of Biophotonics. Among these projects, the teams of Prof. D. Côté (Physics), Prof. M. Parent (Neuroscience) and Prof. Y. Messaddeq (Physics) have conceived a fibered coherent Raman spectroscopy system for the observation of intact primate brain tissue. ${ }^{3}$ Projects involving three trainees of the biophotonics programs in the team of Prof. P. De Koninck (Biochemistry) developed innovative methods using Fluorescence Resonance Energy Transfer (FRET) and Fluorescence Lifetime Imaging Microscopy (FLIM) and super-resolution microscopy for the study of synaptic protein interactions. ${ }^{4}$ The team of Prof. A. Saghatelyan (Neuroscience) in collaboration with the team of Prof. D. Côté (Physics) employed in vitro and in vivo two-photon microscopy for the study of spine relocation of adult-born interneurons in the olfactory bulb. ${ }^{5}$ The collaboration between the teams of Prof. D. Côté (Physics) and Prof. Y. De Koninck (Neuroscience) lead to fruitful multidisciplinary research projects on large scale in vivo nonlinear imaging of morphometry of nerve fibers. ${ }^{6}$ The team of Prof. S. Rainville (Physics) in collaboration with Prof. T. Galstian (Physics) studied bacteria motility with optical approaches. ${ }^{7}$ Recently, the team of Prof. F. Lavoie-Cardinal (Physics) in collaboration with the team of Prof. P. De Koninck (Biochemistry), developed 


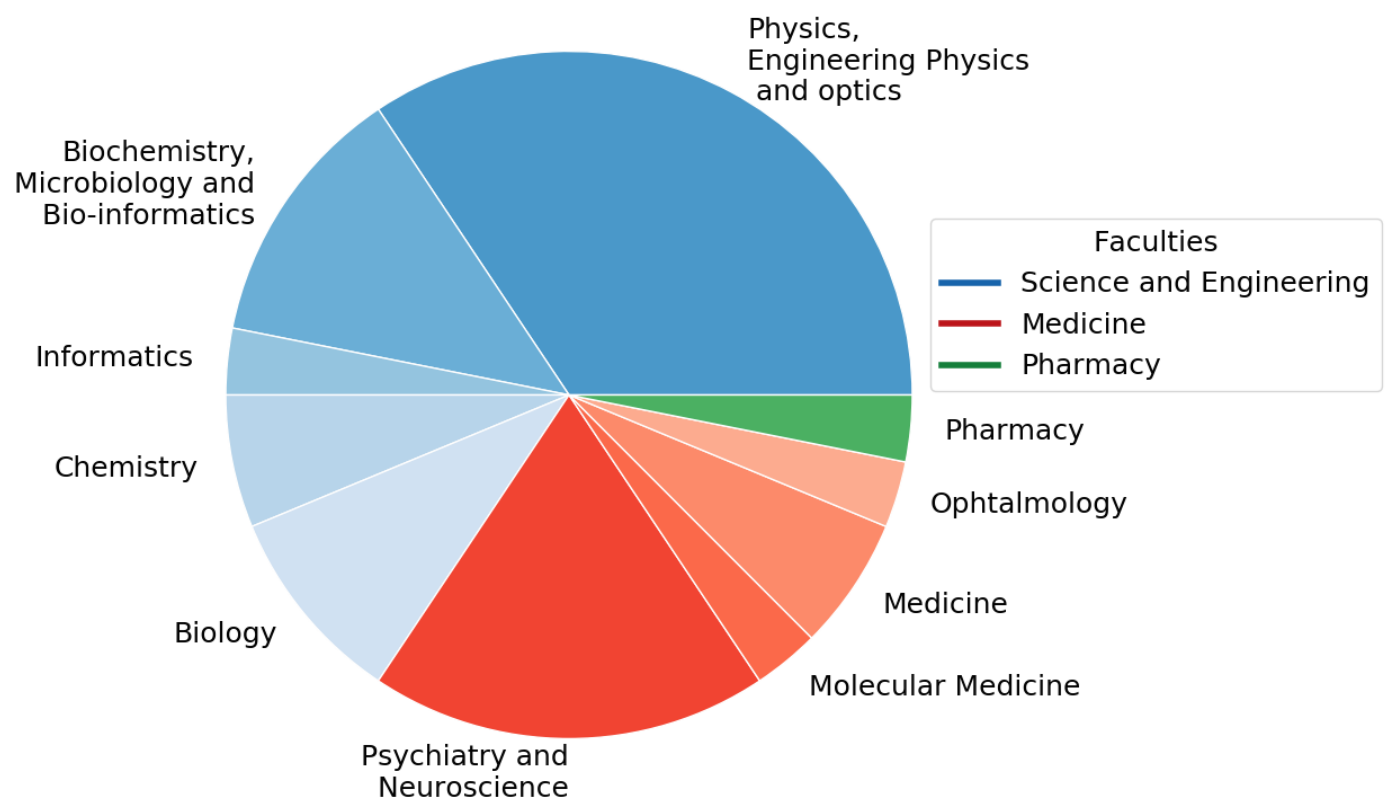

Figure 3. Departmental and faculty affiliations of co-supervisors in the biophotonics Programs. Pie sections indicate their departmental affiliation, while the colors indicate their faculty.

machine learning assisted super-resolution microscopy approaches for the study of synaptic protein reorganization and multi-modal imaging. ${ }^{8}$ Students have also had the opportunity to present their work at different conferences such as Canadian Association for Neuroscience (CAN), Frontiers in Neurophotonics (FINS), Society for Neurosciences, Photonics West (OSA) and Biophotonics (OSA).

\section{FRONTIERS IN NEUROPHOTONICS SUMMER SCHOOL (FINSS)}

One of the mandatory courses of the Masters program in biophotonics is the Frontiers in Neurophotonics summer school (FINSS), which welcomes 20 students from around the world per year at the Neurophotonics Centre /CERVO Brain research centre. FINSS will be in its $13^{\text {th }}$ edition this year and has contributed to the training of over 250 graduate students and post-docs from more than 20 different countries since its inception in 2007. It combines tutorials given by experts in photonics and neuroscience and hands-on experiments involving advanced optical approaches to measure, manipulate and follow molecular events in living neuronal cells. Topics covered during the school range from super-resolution imaging of subcellular components in neurons to large scale in vivo calcium imaging during a variety of behavioural tasks. At the end of the course, trainees get the chance to plan and carry out their own short experiment (mini-project) with the help of the schools tutors.

FINSS is also an opportunity for the students to meet fellow researchers and students from around the world, discuss and discover the latest advances in live cell optical imaging techniques put in perspective by experimental challenges in the field of neuroscience.

\section{TRAINING ENVIRONMENT}

\subsection{The Neurophotonics Centre}

Amongst the highly specialized training environments made available to the students of the biophotonics program is the Neurophotonics Centre. Established in 2004 inside the CERVO Brain research centre, the Neurophotonics Centre is a unique, state-of-the-art national facility for advanced biophotonics approaches dedicated toward the understanding of the brain, the development of diagnostics for brain disorders and phototherapy. The Centre 
Daily schedule

\begin{tabular}{|c|c|c|}
\hline & Days 1-5 & Days 7-10 \\
\hline \multirow{2}{*}{ AM } & Didactic seminar 1 & Didactic seminar \\
\hline & Didactic seminar 2 & \multirow[b]{3}{*}{ Projects } \\
\hline \multirow[b]{2}{*}{ PM } & $\begin{array}{c}\text { Experiment } \\
\text { demonstrations }\end{array}$ & \\
\hline & $\begin{array}{c}\text { Hands-on } \\
\text { lab experiments }\end{array}$ & \\
\hline Evening & $\begin{array}{l}\text { Data analysis, } \\
\text { Poster session, } \\
\text { Social activites }\end{array}$ & Data analysis \\
\hline
\end{tabular}

Hands-on experiments

- In vivo imaging of microglial activation

- Multiphoton calcium imaging in zebrafish

- Super-resolution microscopy

- Digital holographic microscopy

- In vivo mesoscopic imaging

Calcium imaging in freely behaving mice

- Wireless In vivo electric measurements

- High-speed microscopy

- Lightsheet microscopy

- In vivo optogenetics

- Multiple fibre photometry

\section{3th edition}

FRONTIERS IN

Figure 4. Overview of the Frontiers in Neurophotonics Summer School. Adapted from Ref. 9

presently occupies 30,000 sq. ft. It includes 6 clean rooms, 46 microscopy rooms, wet labs, cold rooms, tissue culture rooms, histology rooms, and a workshop for instrument design. The centre brings together a team of researchers, scientists, graduate students and staff who develop and use the most innovative methods integrating neuroscience and physics.

The Neurophotonics Centre is also the nexus of the Canadian Neurophotonics Platform, a technology platform that drives development and maximizes exploitation of leading-edge photonics technologies for the study, diagnostics and treatment of brain diseases. The Neurophotonics Platform is a coast-to-coast initiative regrouping 7 institutions (Dalhousie, Laval, McGill, U of Ottawa, U of Calgary, U of Alberta, UBC) bringing together the complementary expertise of leading Canadian chemists, physicists, neurobiologists and computational scientists who work in collaboration to develop and test novel neurophotonics tools and technologies. This close collaboration generates a rapid feedback loop for development of novel tools, which in turn accelerates development of these tools. At the core of its mandates also lies the training of highly qualified personnel, which on top of the existing Neurophotonics summer school also brings the possibility of year-round training by exchanges of trainees amongst the 7 participating institutions across Canada.

\subsection{Centre d'Optique Photonique et Lasers (COPL)}

The COPL is the Quebec cluster of recognized experts in optics and photonics. Its research excellence, state-ofthe-art facilities and comprehensive scientific program position the COPL among the best centres in the world for 
optics and photonics training and research. The majority of its activities takes place on the campus of Université Laval, in the Pavillon d'Optique Photonique (POP). The POP is a 10,000 $\mathrm{m}^{2}$ building opened in 2006 solely dedicated to research in optics and photonics. Lab space in a clean room environment takes up two thirds of the area. The Centre is equipped with fiber-optic fabrication and characterization facilities, thin film deposition systems, femtosecond lasers and sophisticated optical test and measurement instruments.

\subsection{Sentinel North strategy}

Université Laval obtained Funding from the Canada First Research Excellence Fund to develop the Sentinel North Strategy. It draws on over a half-century of northern and optics/photonics research to develop innovative new technology, train the next generation of transdisciplinary researchers and improve our understanding of the northern environment and its impact on human beings and their health. ${ }^{10}$ The biophotonics graduate programs are at the heart of the Sentinel North training initiative, which in return enriches the programs through bootcamps, summer/winter schools and new graduates courses, such as Light and Environment.

\section{CONCLUSION}

The graduate programs in biophotonics at Université Laval are training a new generation of highly qualified personnel at the interface of optics/photonics and life sciences to meet the transdisciplinary needs of the industry, basic research, and the new societal challenges. Biomedical, biotechnology, food, and high tech industry show a marked interest for the trainees, rapidly recruiting graduates of the biophotonics programs. In addition to providing transdisciplinary training, the $\mathrm{PhD}$ program in biophotonics prepares the student for positions with significant responsibilities for the design, supervision and execution of research in the field that will be beneficial for academic research and industry. Biophotonics graduates contribute to society through the development of knowledge, new practices and new technologies essential to health and to many multidisciplinary industries.

\section{REFERENCES}

[1] Laval, U., "Maîtrise en biophotonique - avec mémoire (M. Sc.)." ULaval, 2018-11-21 https ://www . ulaval. $\mathrm{ca} /$ les-etudes/programmes/repertoire/details/maitrise-en-biophotonique-avec-memoire-m-sc. html. (Accessed: 26 April 2019).

[2] Laval, U., "Doctorat en biophotonique (Ph. D.)." ULaval, Version: 2018-11-21 https://www.ulaval.ca/ les-etudes/programmes/repertoire/details/doctorat-en-biophotonique-ph-d.html. (Accessed: 26 April 2019).

[3] DePaoli, D. T., Lapointe, N., Messaddeq, Y., Parent, M., and Côté, D. C., "Intact primate brain tissue identification using a completely fibered coherent raman spectroscopy system," Neurophotonics 5(3), 035005 (2018).

[4] Tardif, C., Nadeau, G., Labrecque, S., Côté, D., Lavoie-Cardinal, F., and De Koninck, P., "Fluorescence lifetime imaging nanoscopy for measuring förster resonance energy transfer in cellular nanodomains," Neurophotonics 6(1), 015002 (2019).

[5] Breton-Provencher, V., Bakhshetyan, K., Hardy, D., Bammann, R. R., Cavarretta, F., Snapyan, M., Côté, D., Migliore, M., and Saghatelyan, A., "Principal cell activity induces spine relocation of adult-born interneurons in the olfactory bulb," Nature communications 7, 12659 (2016).

[6] Bégin, S., Dupont-Therrien, O., Bélanger, E., Daradich, A., Laffray, S., De Koninck, Y., and Côté, D. C., "Automated method for the segmentation and morphometry of nerve fibers in large-scale cars images of spinal cord tissue," Biomedical optics express 5(12), 4145 (2014).

[7] Duchesne, I., Galstian, T., and Rainville, S., "Transient locking of the hook procures enhanced motility to flagellated bacteria," Scientific reports 7(1), 16354 (2017).

[8] Durand, A., Wiesner, T., Gardner, M.-A., Robitaille, L.-É., Bilodeau, A., Gagné, C., De Koninck, P., and Lavoie-Cardinal, F., "A machine learning approach for online automated optimization of super-resolution optical microscopy," Nature communications 9 (2018).

[9] Laval, U., "Frontiers in neurophotonis." Neurophotonics Centre https://neurophotonics.ca/ frontiers-in-neurophotonics-summer-school. (Accessed: 26 April 2019).

[10] Laval, U., "Sentinel North." ULaval https://sentinellenord.ulaval.ca/en/. (Accessed: 26 April 2019). 